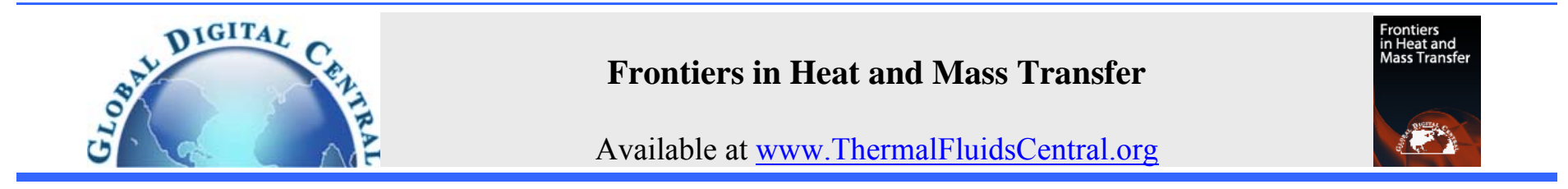

\title{
FINITE ELEMENT STUDY OF DDNC IN BOTTOM HEATED ENCLOSURES WITH MASS DIFFUSIVE SIDE WALLS
}

\author{
Nithish Reddy ${ }^{*}$, K. Murugesan \\ Mechanical \& Industrial Engineering Department, Indian Institute of Technology Roorkee, Roorkee - 247 667, India
}

\begin{abstract}
In this paper DDNC phenomenon in a bottom heated enclosure exposed to mass diffusion from its side walls is investigated numerically. The interplay between thermal and solutal buoyancy forces on fluid circulation and heat transfer rates is studied in three different enclosures of aspect ratios 0.5 , 1.0 and 2.0. Finite element base numerical code has used to solve the governing equations, here velocity and vorticity are taken as primary variables for flow field. Numerical results are well validated with that of the literature. The relative strength of solutal to thermal buoyancy forces is defined by buoyancy ratio parameter ' $\mathrm{N}$ ', numerical investigations were carried out for different values of $\mathrm{N}$ in the range of 0 to 10 and three different Rayleigh numbers $\left(\mathrm{Ra}=1.0 \times 10^{3}, 1.0 \times 10^{4}, 1.0 \times 10^{5}\right)$. From results it is observed that solutal buoyancy forces broken down the larger fluid cells and promoted local circulations of stronger strength. Increase in contribution of solutal buoyancy force has resulted in a maximum of $12.6 \%, 14.5 \%$ and $51 \%$ increase in average Nusselt number for shallow, square and deep enclosures respectively when heat transfer is primarily by convection while the effect of buoyancy ratio is not felt much on heat transfer at diffusion dominant conditions i.e at $\mathrm{Ra}=1.0 \times 10^{3}$.
\end{abstract}

Keywords: natural convection, cavity, buoyancy ratio, double diffusive

\section{INTRODUCTION}

Double diffusive natural convection (DDNC) flows are widely seen in many industrial systems such as CVD chambers, food processing units, chemical engineering setups etc. where it's important to study fluid and heat flow patterns for various reasons. Natural convection phenomenon in enclosures is one of the widely studied research subject over years due to its importance in many practical applications (Heather et al., 2013; Manoj et al., 2014). Since last decade there is an increasing level of interest among the researchers in studying the flow behavior and heat transfer mechanism in the enclosures under the combined influence of thermal and solutal buoyancy forces. These problems are also called as double diffusive natural convection (DDNC) or thermo-solutal convection problems. Such type of fluid convection is usually encountered in many mechanical and chemical engineering systems and in numerous geophysical phenomena, including convection in the oceans, in the earth's outer core etc.(Wang et al. 2014; Aouachria et al., 2012; Kaladhar and Srinivasacharya, 2014; Manoj et al., 2015; Kumar et al., 2011).Because of their wide importance double diffusive convection flows are studied in different types of systems by various researchers.

An initial experimental work on DDNC has been conducted in low aspect ratio rectangular enclosures whose side walls are differentially heated and salted (kamotani et al., 1985). They reported that study of flow structures in such conditions with wide difference in diffusion rates is important for crystalline growth applications. Costa et al., (1997) established a numerical model for double diffusive natural convection phenomenon in an enclosure with mass diffusive wall using moist air as medium. This model could effectively visualise heat and mass lines throughout the enclosure. Beghein et al. (1992) carried out research on DDNC in a differentially heated and salted square enclosure where the main focus was kept on understanding the effect of solutal buoyancy forcesfor a fixed thermal Rayleigh number $\left(10^{7}\right)$, they gave correlations for Nusselt number and Sherwood number for the range of parameters considered in their research. Later Nishimura et al. (1998) came up with newer perspective of examining the formation of fluid cells under different buoyancy ratios. They addressed the oscillatory behaviour of the convection cells with change in buoyancy ratio parameter N. Hyun and Lee (1990) made an attempt to understand the nature of DDNC in the case of rectangular enclosure and exposed the major discrepancies in evolution pattern between cooperating and opposing flows through stream lines, temperature and concentration plots. More extensive study on the effect of different parameters on DDNC phenomenon was carried out by Chen et al. (2010). They have chosen higher Rayleigh number regime $\left(10^{6}\right.$ and $\left.10^{7}\right)$, different aspect ratios $(0.5-2.0)$ and buoyancy ratios $(0.8<\mathrm{N}<1.3)$. Results shown that at $\mathrm{Ra}=10^{6}$ only one fluid cell is observed for different aspect ratios but for buoyancy ratios greater than unity, a number of vortices were generated and they varied with change in enclosure aspect ratio. Few works concentrated on the study of DDNC phenomenon in enclosures with higher aspect ratios.

Among them Han and Kuhn (1991) figured out that at aspect ratio 4 in a differentially heated enclosure, an unicell flow was observed without any clear demarcation weather the case is pure solutal dominant one or pure thermal dominant one. Chouikh et al. (2007) analysed DDNC in an inclined glazing enclosure of aspect ratio 10 resembling the solar distillation set up. It was observed that the formation of single rotating cell is found to be favourable for allowing sufficient time for vapour to cool down and better performance of solar distiller. Qin et al. (2014) investigated double diffusive convection in a differentially heated rectangular enclosure of aspect ratio 2 using a compact difference method. Alloui et.al. (2010) considered the soret effect in their analysis on DDNC in a very shallow enclosure filled

*Corresponding author.Email: krimufme@iitr.ac.in 
with binary mixtures subjected to solutal flux on horizontal boundaries. Few investigations (Nikbakthi and Rahimi, 2012; Khodakhah and Nikbakthi, 2016; Oueslati et al., 2014; Jenaa et al., 2015) were carried out on doublediffusive natural convection in cavities whose side walls are partially heated and cooled.. Nazari et al. (2015), Moufekkir et al. (2015) and Ren et al. (2016) numerically investigated double diffusive natural convection in cavities using Lattice Boltzmann method. Corcione et al. (2015) gave correlations for the ddnc in square enclosures induced by opposite temperature and concentration gradients.

It has been observed that most of the works carried out till date dealt with interaction of thermos-solutal buoyancy forces in traditional differentially heated enclosures, otherwise very limited outcomes are available in the literature on other models of heating and salting. In the current study an attempt is made to investigate the heat and fluid flow characteristics in bottom heated enclosure subjected to mass diffusive side walls. Numerical experiments were conducted on enclosures of three different aspect ratios 0.5 (shallow), 1.0 (square) and 2.0(deep) and results are discussed. The effect of interplay between thermal and solutal buoyancy forces on fluid convection and heat transfer has been explored for $0<\mathrm{N}<10,10^{3}<\mathrm{Ra}<10^{5}$

\section{GOVERNING EQUATIONS}

Flow is considered in compressible and Boussinesq approximation is assumed for density variations. The following are the governing equations that are solved for the present double diffusive convection problem.

Vorticity transport equation:

$$
\begin{aligned}
& \frac{\partial \boldsymbol{\omega}}{\partial t}+(\boldsymbol{V} \cdot \nabla) \boldsymbol{\omega}=v \nabla^{2} \boldsymbol{\omega}+\nabla \times\left[g \beta_{T}\left(T-T_{\infty}\right)\right] \\
& +\nabla \times\left[g \beta_{c}\left(C-C_{\infty}\right)\right]
\end{aligned}
$$

where $T$ is temperature, $C$ is concentration, $\boldsymbol{V}=(u, v)$ are the velocity components in $x$ - and $y$-directions respectively, $\omega$ is the vorticity component.

Velocity- Poisson equation:

$\nabla^{2} \boldsymbol{V}=-\nabla \times \omega$

Energy equation:

$$
\frac{\partial T}{\partial t}+\boldsymbol{V} \cdot(\nabla T)=\alpha \nabla^{2} T
$$

Solutal concentration equation:

$$
\frac{\partial C}{\partial t}+\boldsymbol{V} \cdot(\nabla C)=D \nabla^{2} C
$$

Equations (1),(2),(3) and (4) are the converted in to non-dimensional form by applying the following scaling parameters Spatial coordinates, $\mathrm{X}=\mathrm{x} / \mathrm{L}, \mathrm{Y}=\mathrm{y} / \mathrm{L}$, velocities, $\mathrm{U}=\mathrm{uL} / \alpha, \mathrm{V}=\mathrm{vL} / \alpha$, vorticity, $\varsigma$ $=\omega \mathrm{L}^{2} / \alpha$, time, $\tau=\alpha \mathrm{t} / \mathrm{L}^{2}$, temperature $\Theta=\mathrm{T}-\mathrm{T}_{\mathrm{c}} / \mathrm{T}_{\mathrm{h}}-\mathrm{T}_{\mathrm{c}}$ and solutal concentration $\phi=\mathrm{C}-\mathrm{C}_{\mathrm{c}} / \mathrm{C}_{\mathrm{h}}-\mathrm{C}_{\mathrm{c}}$. After substituting the above scaling parameters the dimension form of governing equations are transformed as the following.

Vorticity transport equation:

$$
\begin{aligned}
& \frac{\partial \zeta}{\partial \tau}+U \frac{\partial \zeta}{\partial X}+V \frac{\partial \zeta}{\partial Y}=\operatorname{Pr}\left(\frac{\partial^{2} \zeta}{\partial X^{2}}+\frac{\partial^{2} \zeta}{\partial Y^{2}}\right)+ \\
& \operatorname{Ra} \operatorname{Pr}\left(N \frac{\partial \phi}{\partial X}+\frac{\partial \theta}{\partial Y}\right)
\end{aligned}
$$

Velocity Poisson equation

$$
\begin{aligned}
& \frac{\partial^{2} U}{\partial X^{2}}+\frac{\partial^{2} U}{\partial Y^{2}}=-\frac{\partial \varsigma}{\partial Y} \\
& \frac{\partial^{2} V}{\partial X^{2}}+\frac{\partial^{2} V}{\partial Y^{2}}=\frac{\partial \varsigma}{\partial X}
\end{aligned}
$$

Energy equation

$$
\frac{\partial \theta}{\partial \tau}+U \frac{\partial \theta}{\partial X}+V \frac{\partial \theta}{\partial Y}=\frac{\partial^{2} \theta}{\partial X^{2}}+\frac{\partial^{2} \theta}{\partial Y^{2}}
$$

Solutal concentration equation

$$
\frac{\partial \phi}{\partial \tau}+U \frac{\partial \phi}{\partial X}+U \frac{\partial \phi}{\partial Y}=\frac{1}{L e}\left(\frac{\partial^{2} \phi}{\partial X^{2}}+\frac{\partial^{2} \phi}{\partial Y^{2}}\right)
$$

where non-dimensional numbers are defined as, Rayliegh number $\mathrm{Ra}=\mathrm{g} \beta_{\mathrm{T}} \Delta \mathrm{TH}^{3} / \nu \alpha$, buoyancy ratio $\mathrm{N}=\beta_{\mathrm{c}} \Delta \mathrm{C} / \beta_{\mathrm{T}} \Delta \mathrm{T}=\mathrm{GR}_{\mathrm{s}} / \mathrm{GR}_{\mathrm{T}}$, Prandtl number, $\operatorname{Pr}=v / \alpha$ and $\mathrm{Le}=\mathrm{Sc} / \mathrm{Pr}$.

These non-dimensional equations (Eqs. (5) to (8)) are then reduced to weak form by applying Galerkin's weighted residual finite element method, integrated over the elements to finally obtain the matrix form at element level as presented below.

Vorticity transport equation:

$$
\begin{aligned}
& {\left[\left[C_{i j k}\right]+\theta \Delta t \times \operatorname{Pr}\left[K_{i j k}\right]+\theta \Delta t\left[G_{i j k}^{n}\right]\right]\left\{\varsigma_{i k}^{n+1}\right\}} \\
& =\left[C_{i j k}\right]\left\{\varsigma_{i k}^{n}\right\}-(1-\theta) \Delta t \times \operatorname{Pr}\left[K_{i j k}\right]\left\{\varsigma_{i k}^{n}\right\} \\
& +\operatorname{Ra} \operatorname{Pr} \times \Delta t N\left[S_{i j k}\right]\left\{\Phi_{i k}^{n}\right\}+\operatorname{Ra} \operatorname{Pr} \Delta t\left[S_{i j k}\right]\left\{\Theta_{i k}^{n}\right\} \\
& -(1-\theta) \Delta t\left[G_{i j k}^{n}\right]\left\{\varsigma_{i k}^{n}\right\}
\end{aligned}
$$

Velocity Poisson equations:

$$
\begin{aligned}
& {\left[K_{i j k}\right]\left\{U_{i k}\right\}=\left[T_{i j k}\right]\left\{\varsigma_{i k}\right\}} \\
& {\left[K_{i j k}\right]\left\{V_{i k}\right\}=-\left[S_{i j k}\right]\left\{\varsigma_{i k}\right\}}
\end{aligned}
$$

Energy equation

$$
\begin{aligned}
& {\left[\left[C_{i j k}\right]+\theta \Delta t\left[K_{i j k}\right]\right]\left\{\Theta_{i k}^{n+1}\right\}=\left[C_{i j k}\right]\left\{\Theta_{i k}^{n}\right\}} \\
& -(1-\theta) \Delta t\left[K_{i j k}\right]\left\{\Theta_{i k}^{n}\right\}-\Delta t\left[G_{i j k}^{n}\right]\left\{\Theta_{i k}^{n}\right\}
\end{aligned}
$$

Solutal concentration equation

$$
\begin{aligned}
& {\left[\left[C_{i j k}\right]+\theta \Delta t\left[K_{i j k}\right]\right]\left\{\Phi_{i k}^{n+1}\right\}=\left[C_{i j k}\right]\left\{\Phi_{i k}^{n}\right\}-} \\
& \frac{(1-\theta) \Delta t}{L e}\left[K_{i j k}\right]\left\{\Phi_{i k}^{n}\right\}-\Delta t\left[G_{i j k}^{n}\right]\left\{\Phi_{i k}^{n}\right\}
\end{aligned}
$$

where $\mathrm{i}, \mathrm{j}$ and $\mathrm{k}$ are the element, row and column indices respectively and $\theta$ is a weighting factor for time discretization with range, $0 \leq \theta \leq 1$, and 


$$
\begin{aligned}
& {\left[G_{i j k}^{n}\right]=\int_{X Y_{e}} N_{j} \frac{\partial N_{k}}{\partial X} N_{l} U_{l}^{n} d X d Y+\int_{X Y_{e}} N_{j} \frac{\partial N_{k}}{\partial Y} N_{l} V_{l}^{n} d X d Y} \\
& {\left[K_{i j k}\right]=\int_{X Y_{e}}\left(\frac{\partial N_{j}}{\partial X} \frac{\partial N_{k}}{\partial X}+\frac{\partial N_{j}}{\partial Y} \frac{\partial N_{k}}{\partial Y}\right) d X d Y} \\
& {\left[C_{i j k}\right]=\int_{X Y_{e}} N_{j} N_{k} d X d Y} \\
& {\left[T_{i j k}\right]=\int_{X Y_{e}} N_{j} \frac{\partial N_{k}}{\partial Y} d X d Y} \\
& {\left[S_{i j k}\right]=\int_{X Y_{e}} N_{j} \frac{\partial N_{k}}{\partial X} d X d Y}
\end{aligned}
$$

An Isoparametric formulation is used to transform the global coordinates into local coordinate system so that the Gaussian quadrature can be employed for the numerical integration of all the terms in the weighted governing equations.

\section{SOLUTION METHODOLOGY}

The above shown final equations of vorticity, velocity poison, energy and concentration are solved over computation domain with appropriate initial and boundary conditions. The solution domain is first discretized into a number of bilinear iso-parametric elements and for each element the partial differential governing questions are approximated using discretization techniques. Second order-accurate Crank-Nicolson scheme is used for discretization of time derivatives. To minimize the residual in the computational domain formed as consequences of approximation an iterative computational procedure is followed till the error in thermal, solutal and flow fields reduces to specified value i.e $10^{-5}$. Once the solution in all the flow fields is converged at the present time level, the iteration procedure is repeated to solve for the next time level. The algebraic equations obtained at each node are solved without assembling using global matrix free algorithm. Conjugate gradient iterative solver is employed for the solution of the final nodal equations.

\section{Computational algorithm}

The below shown computation procedure followed to obtain numerical solution

(i) Perform the integral operations for all element matrices as shown in equations (9) to (12)

(ii) Determine the elements surrounding each boundary node for vorticity, velocity, temperature and solutal concentration fields based on the specified Dirichlet boundary conditions.

(iii) Start computing over entire domain for solution at $\mathrm{t}=\mathrm{t}+\Delta \mathrm{t}$.

(a) Initialize the vorticity field

(b) Enforce velocity boundary conditions at element level and solve for velocity field using velocity Poisson equations.

(c) Using the components of velocity obtained in previous step over flow domain compute for vorticity values at the boundaries.

(d) Obtain vorticity field by solving vorticity transport equation after enforcing vorticity boundary conditions at elemental level.

(e) Obtain temperature field by solving the corresponding energy equations after enforcing the thermal boundary conditions.

(f) Obtain for solutal field by solving the corresponding solutal concentration equations after enforcing the boundary conditions. (g) Repeat steps $(a)$ to $(f)$ until the field variables velocities, vorticity temperature and solutal concentration are converged at current time level.

(iv) Go to step (iii) for the next time step.

Computational domain

The schematic diagram of the problem domain is shown in Figure1. Bottom wall is kept hot and top wall is maintained cold, while both the vertical walls are assumed adiabatic to heat flow.No-slip boundary conditions for velocity components are assumed on each

of the boundaries. Adiabatic solutal boundary conditions are chosen on both horizontal walls and a linearly varying concentration profile is assumed along the vertical walls as shown in Figure1. In the current work the change in heat and fluid flow pattern with increase in strength of solutal buoyancy forces has been studied for different parameters in the enclosures of aspect ratio $0.5,1$ and 2. Initial and boundary conditions chosen for the present problem are given in the following equations.

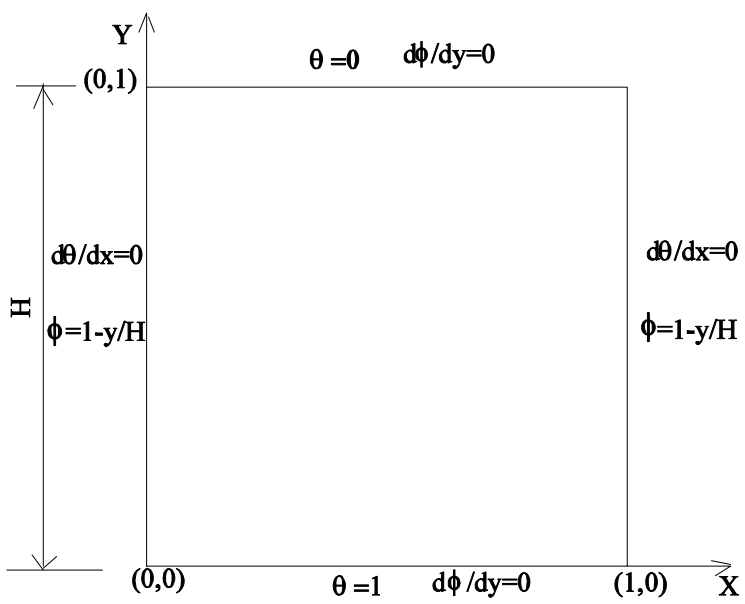

Fig. 1 Schematic diagram

Initial and boundary conditions:

Initial

conditions:

(a) $\tau=0, \quad \mathrm{U}=\mathrm{V}=\Theta=\Phi=0$

Boundary conditions for $\tau>0$

$$
\begin{aligned}
& \mathrm{U}=\mathrm{V}=0, \Theta=1, \frac{\partial \Phi}{\partial \boldsymbol{y}}=0 \text { at } \mathrm{Y}=0 \text { for } 0<\mathrm{X}<1 \\
& \mathrm{U}=\mathrm{V}=0, \Theta=0, \frac{\partial \Phi}{\partial y}=0 \text { at } \mathrm{Y}=1 \text { for } 0<\mathrm{X}<1 \\
& \mathrm{U}=\mathrm{V}=0, \frac{\partial \Theta}{\partial X}=0, \Phi=1-\mathrm{y} / \mathrm{H} \text { at } \mathrm{X}=0 \text { and } \mathrm{X}=1 \text { for } 0<\mathrm{Y}<1
\end{aligned}
$$

\section{MESH SENSITIVITY AND VALIDATION}

Structured non-uniform mesh has been used in the current work; figure 2 gives the picture of computational mesh used for square cavity. Transfinite interpolation(TFI) method is used to generate computational grid. The computer code developed has been tested for grid independence for double diffusive natural convection in enclosures with aspect ratios $0.5,1$ and 2 for $\mathrm{N}=10$ and $\mathrm{Ra}=10^{4}$ using three different meshes. 


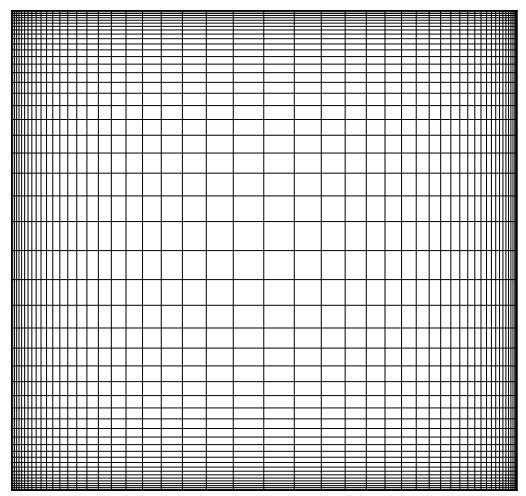

Fig. 2 Computational mesh

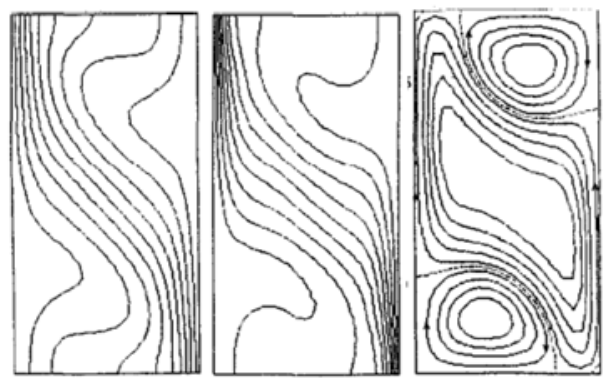

Nishimura et al.(1998)
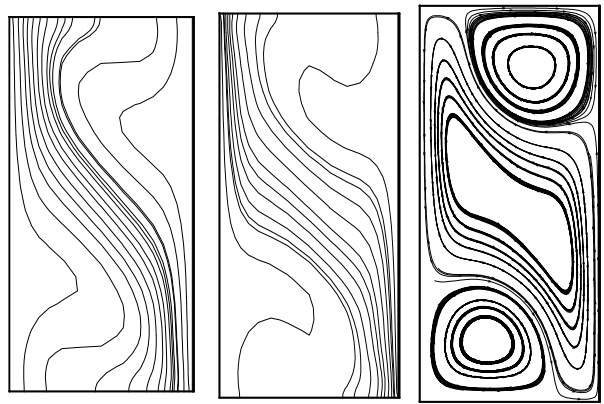

Present

Fig. 3 Iso-therms, iso-concentration and stream line comparisons at $\mathrm{Ra}=1.0 \mathrm{e} 5, \mathrm{~N}=0.8$.

Average Nusselt number has been taken as the parameter for comparison of the performance of three meshes and the results obtained are shown in Table 1. From the table one can observe that the error between two consecutive meshes, M1 and M2 and M2 and M3 keeps decreasing with refinement of meshes. As the error between meshes M2 and M3 is much less than 1\%, mesh M2 has been used in all the simulation for the test problems discussed in the paper. For the purpose of validation, double diffusive natural convection in a enclosure considered by Turan et al.(2012) has been considered.

Results obtained for the average Nusselt number for $\mathrm{Ra}=10^{3}$ to $10^{5}$ are compared with the results of Turan et al. (2012) as shown in Tables 2(a) and 2(b) for $\operatorname{Pr}=1$ and 10 respectively. It can be seen from these results that the present code is able to predict the Nusselt number with a maximum error of $1 \%$ compared to the results reported by Turan et al.(2012). Other than the Nusselt numbers, isotherms, isoconcentration and streamlines are also compared with the results of Nishimura et al. (1998) for the purpose of validation. Figure 3 shows the comparison of the present results for the above contours with the above reference. It can be observed that the contours presented by the present research resemble almost the same patterns of contours reported by Nishimura et al. (1998).
Table 1 Mesh sensitivity results at $\mathrm{N}=10$ and $\mathrm{Ra}=10^{4}$ for shallow, square and deep cavities.

\begin{tabular}{|c|c|c|c|c|}
\hline s.no & $\begin{array}{c}\text { Aspect } \\
\text { ratio }\end{array}$ & Mesh & Avg Nu & Error(\%) \\
\hline 1 & AR=0.5 & $41 \times 21(\mathrm{M} 1)$ & 2.6007 & \\
\cline { 3 - 5 } & & $51 \times 25(\mathrm{M} 2)$ & 2.6033 & 0.0998 \\
\cline { 3 - 5 } & shallow) & $61 \times 31(\mathrm{M} 3)$ & 2.6042 & 0.0345 \\
\hline 2 & $\begin{array}{c}\text { AR=1 } \\
\text { (square) }\end{array}$ & $41 \times 41(\mathrm{M} 1)$ & 2.1752 & \\
\cline { 3 - 5 } & & $51 \times 51(\mathrm{M} 2)$ & 2.1778 & 0.1239 \\
\cline { 3 - 5 } 3 & AR=2 & $21 \times 61(\mathrm{M} 3)$ & 2.1782 & 0.0138 \\
\cline { 3 - 5 } & ( deep ) & $25 \times 51(\mathrm{M} 2)$ & 1.7374 & \\
\cline { 3 - 5 } & & $31 \times 61(\mathrm{M} 3)$ & 1.7382 & 0.0460 \\
\hline
\end{tabular}

\section{RESULTS AND DISCUSSION}

In the current study numerical investigations were carried out for the bottom heated enclosure with salted side walls as shown in Figure 1. Presence of varying strength concentration source on side walls creates a secondary density difference in the enclosure and initiates a solutal convection accompanying thermal convection. In the present section results corresponding to detailed study on thermo-solutal convection with change in buoyancy ratio at different operating parameters has been presented. The relative strength of solutal to thermal buoyancy forces is denoted by buoyancy ratio $\mathrm{N}$. Here $\mathrm{N}=0$ corresponds to pure thermal convection case and at $\mathrm{N}=10$ solutal convection strongly dominates over thermal. Results corresponding to detailed investigation on flow field, temperature, concentration and Nusselt number are illustrated in the following sections. The Rayleigh number is assumed to vary from $10^{3}$ to $10^{5}$ and buoyancy ratio from 0 to 10 and the results are discussed for three aspect ratios, 0.5, 1.0 and 2.0.

Table 2a Comparison of the present results for $\mathrm{Nu}$ with the benchmark results at $\mathrm{N}=0$ case and $\mathrm{Pr}=1$.

\begin{tabular}{|c|c|c|c|}
\hline $\mathrm{Pr}=1$ & $\mathrm{Ra}=10^{3}$ & $\mathrm{Ra}=10^{4}$ & $\mathrm{Ra}=10^{5}$ \\
\hline Present work & 1.01 & 2.155 & 3.913 \\
\hline $\begin{array}{c}\text { Turan et } \\
\text { al.(2012) }\end{array}$ & 1.0 & 2.162 & 3.934 \\
\hline Error(\%) & 1.0 & 0.324 & 0.533 \\
\hline
\end{tabular}

Table $\mathbf{2 b}$ Comparison of the present results for $\mathrm{Nu}$ with the benchmark results at $\mathrm{N}=0$ case and $\mathrm{Pr}=10$

\begin{tabular}{|c|c|c|c|}
\hline $\mathrm{Pr}=10$ & $\mathrm{Ra}=10^{3}$ & $\mathrm{Ra}=10^{4}$ & $\mathrm{Ra}=10^{5}$ \\
\hline Present work & 1.00 & 2.193 & 3.885 \\
\hline $\begin{array}{c}\text { Turan et al. } \\
(2012)\end{array}$ & 1.0 & 2.188 & 3.868 \\
\hline Error (\%) & 0.00 & 0.2285 & 0.4395 \\
\hline
\end{tabular}

\subsection{Stream line and vorticity patterns}

Figures 4 to 6 show the streamline and vorticity contours in all the three enclosures at different buoyancy ratios for Rayleigh numbers, $10^{5}, 10^{4}$ and $10^{3}$ respectively.

From stream lines at $\mathrm{Ra}=10^{5}$ (see Figure $4 \mathrm{a}$ ) it is observed that at $\mathrm{N}=0$ i.e under pure thermal convection case single circular fluid cell is formed in case of square enclosure $(\mathrm{AR}=1)$. In case of shallow enclosure $(\mathrm{AR}=0.5)$ where relative distance between hot and cold walls is less when compared to adiabatic side walls two such circulation cells are noticed, while a single vertically elongated circulation cell is observed with deep enclosure configuration $(\mathrm{AR}=2)$. Along with these large fluid cells a couple of small cells are observed at one of the diagonally opposite corners. With increase in buoyancy ratio from 0 to 10 , these small circulation cells have grown in size and squeezed the fluid in between to form a quadra cell structure in case of $A R=1$. While 

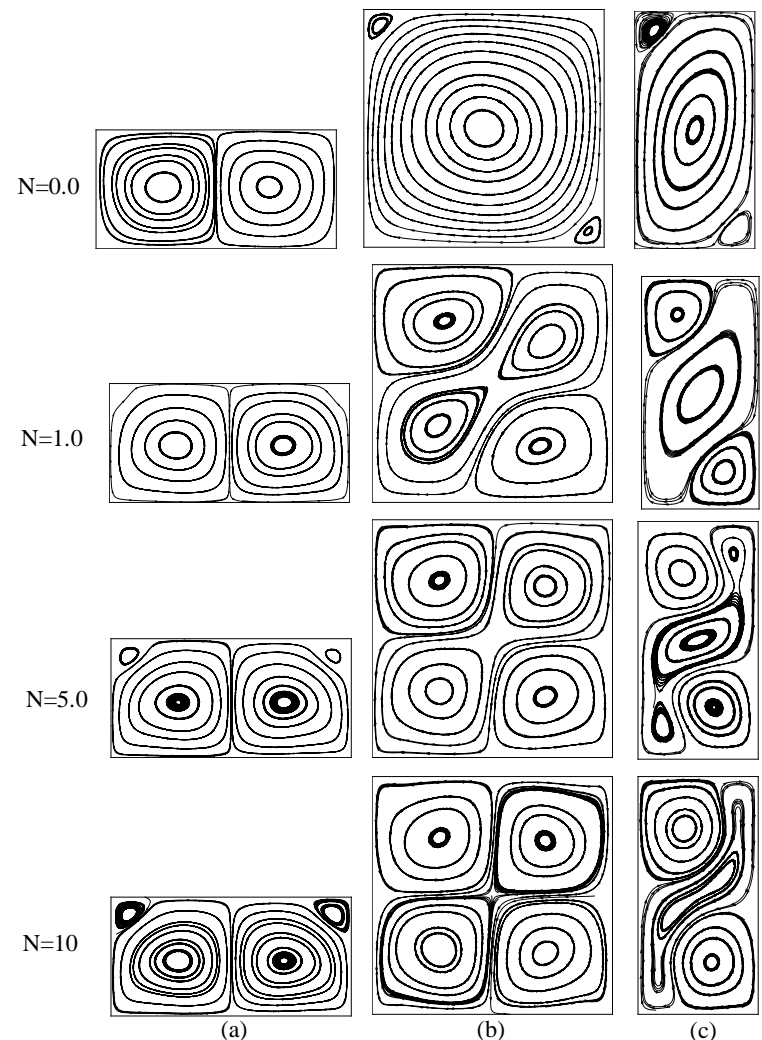

(i)
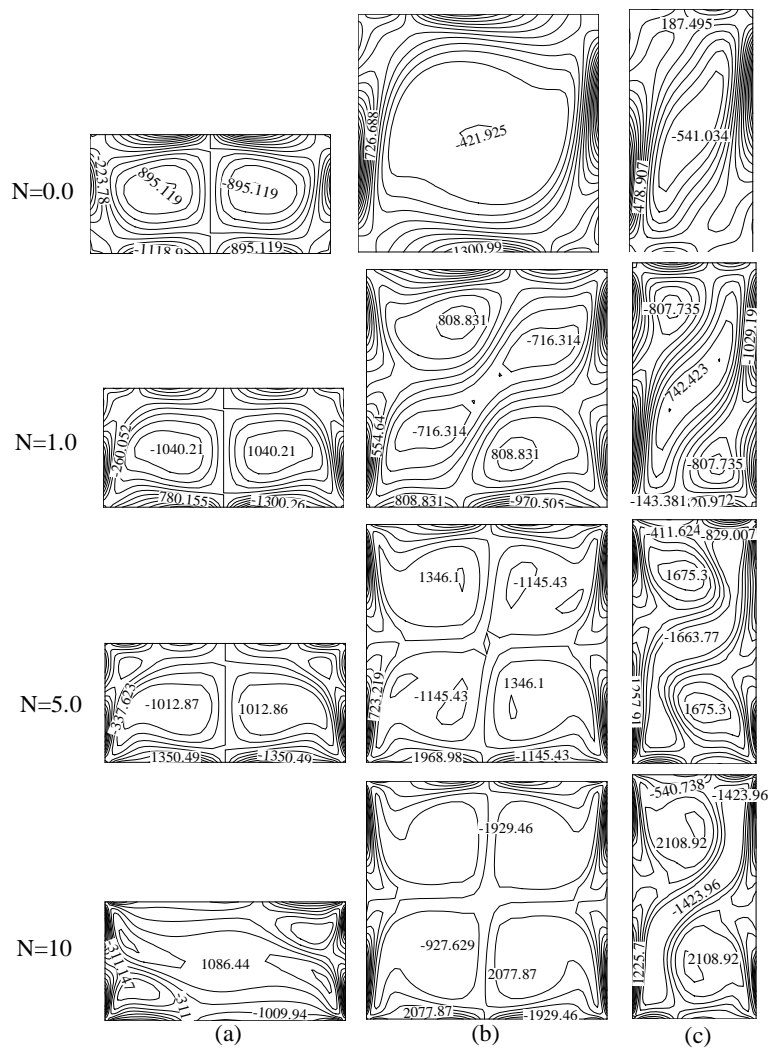

(ii)

Fig. 4 Effect of buoyancy ration on (i)Stream line and (ii) voritcity patterns in cavities of aspect ratios (a)0.5 (b) 1.0 and (c) 2.0 at $\mathrm{Ra}=10^{5}$ for $\mathrm{AR}=2$ case they ended up with a pattern of narrow fluid passage between two large circulations cells. In case of $\mathrm{AR}=0.5$ flow structure has not changed much with increase in buoyancy ratio. From these observations one can say that increase in strength of solutal convection is promoting the formation of multiple fluid circulation cells. Such circulations are favorable for the local mixing of reactant in chemical process but may also create thermal imbalance and no-uniformity at global level. From vorticity results (see Figure $4 b$ ) it is observed that at $\mathrm{N}=0$, square enclosure $(\mathrm{AR}=1.0)$ exhibited low vorticity characteristics and shallow $(\mathrm{AR}=0.5)$ dominated among the three. With increase in buoyancy ratio it is observed that all the three enclosures exhibited increased level of fluid vorticity strength. Thus one can say that increase in contribution of solutal buoyancy forces adding the fluid circulation strength, this is favorable for higher heat transfer rates. Another important observation is higher fluid vorticity is noticed in case of deep enclosure and low with shallow enclosure where thermal boundaries are relatively close.

Figure $5 \mathrm{a}$ and $5 \mathrm{~b}$ presents the stream line and vorticity contours respectively for different buoyancy ratios and aspect ratios in case of Rayleigh number $=10^{4}$. Under relatively weaker buoyancy forces with decrease in Rayleigh number to $\mathrm{Ra}=10^{4}$ a different kind of flow patterns are observed for change in contribution of solutal buoyancy forces. At $\mathrm{N}=0$ stream line pattern remained same for $\mathrm{AR}=0.5$ and $\mathrm{AR}=1.0$ case but for $\mathrm{AR}=2.0$ case duel elongated circular structures are noticed. At $\mathrm{N}=1$ surprisingly Quadra oval structures have formed in case of shallow and deep enclosures, with further increase in $\mathrm{N}$ value these oval shaped structures got slightly deformed in shallow case while in case of deep enclosure two of the diagonally opposite cells tried to merge. A dual circulation cells have noticed in case of square enclosure at $\mathrm{N}=1$, with further increase in $\mathrm{N}$ to 5 and 10 fluid tried to break down into Quadra cells. Interestingly vorticity contours(see Figure $5 \mathrm{~b}$ ) revealed that hardly any circulation strength is noticed in case of shallow and deep cavities at $\mathrm{N}=0$ when flow is purely governed by thermal convection. With introduction of solutal convection i.e. at $\mathrm{N}=1$ some amount of vorticity is noticed, which increased with further increase in $\mathrm{N}$ value. Here square enclosure showed strong circulation strength when compared to other two for all buoyancy ratios. This exposed that both increase and decrease in aspect ratio has resulted in loss of fluid vorticity at $\mathrm{Ra}=10^{4}$.

Figure $6 \mathrm{a}$ and $6 \mathrm{~b}$ reports the stream line and vorticity respectively for shallow, square and deep enclosures for different buoyancy ratio for $\mathrm{Ra}=10^{3}$. At $\mathrm{N}=0$ for pure thermal convection case duel cell structures compatible to enclosure shape are noticed for each aspect ratio. At $\mathrm{N}=1$ Quadra cell structures again in a shape compatible to enclosure shape are recorded. Here at $\mathrm{Ra}=10^{3}$ with weaker buoyancy forces, buoyancy ratio has not shown significant effect on fluid circulation. Any further improvement in buoyancy ratio has not shown any change in fluid circulation pattern. Vorticity contours (see Figure $6 \mathrm{~b}$ ) also reveal that except at $\mathrm{N}=10$ values of vorticity are recorded very low. Thus heat transfer mode can be expected to be purely diffusive in nature in this case and the shape of thus formed fluid cells have not much to offer as they are almost still.

\subsection{Thermal and solutal fields}

Temperature distributions within all the three enclosures are illustrated for different $\mathrm{N}$ values in Figures 7 to 9. At $\mathrm{Ra}=10^{5}$ (Figure 7(i)), when $\mathrm{N}=0$, a similar pattern is observed in case of square and deep enclosure compatible to the shape of the geometry. Isotherms are observed symmetric about mid-section in case of shallow enclosure but with increase in $\mathrm{N}$ value the pattern got upside down, this may be due to reverse in the direction of rotation of fluid cells. With increase in buoyancy ratio thermal gradients near bottom wall became denser for square, shallow, deep enclosures. At $\mathrm{N}=10$, sharp and strong temperature gradients are observed in all the three enclosures., these contours are observed symmetric about mid-section of enclosure as similar to stream line pattern. With decrease in Rayleigh number to $10^{4}$ (Figure $8(\mathrm{i})$ ), at $\mathrm{N}=0$, the thermal buoyancy force is found sufficient 

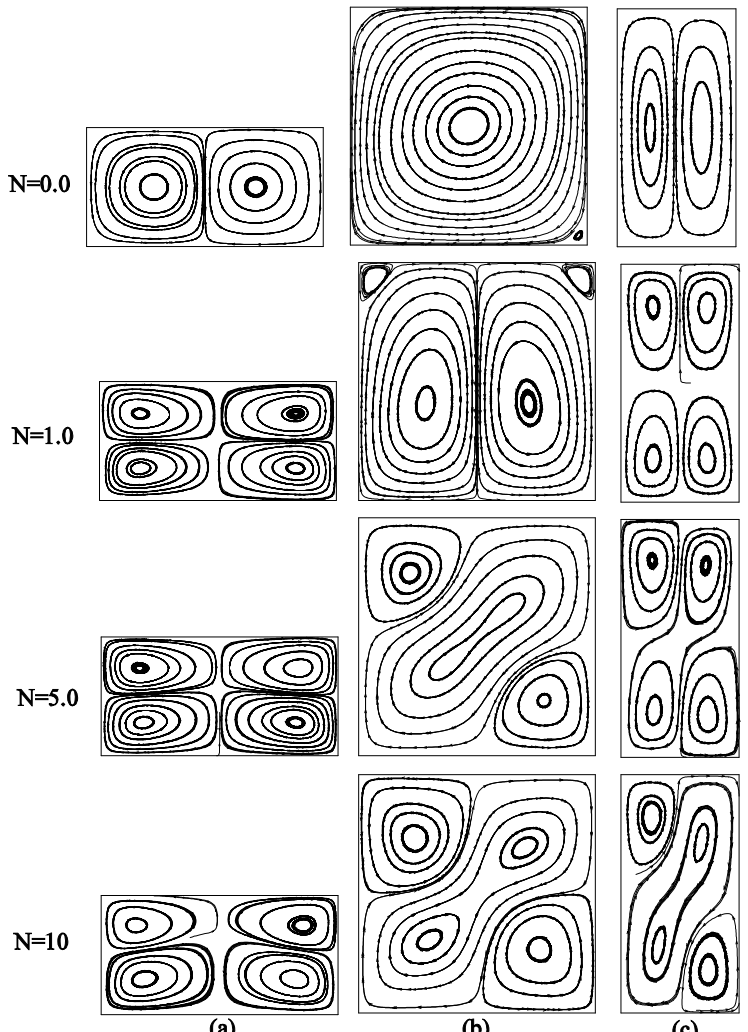

(i)
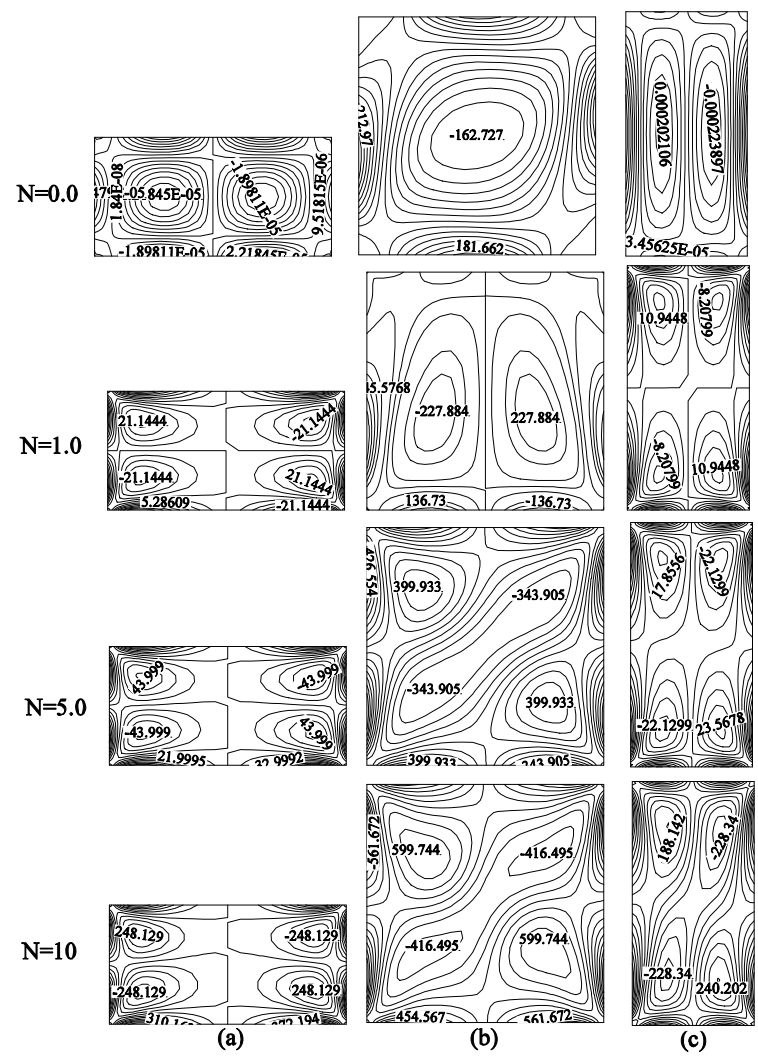

(ii)

Fig. 5 Effect of buoyancy ration on (i)Stream line and (ii) voritcity patterns in cavities of aspect ratios (a) 0.5 (b) 1.0 and (c) 2.0 at $\mathrm{Ra}=10^{4}$

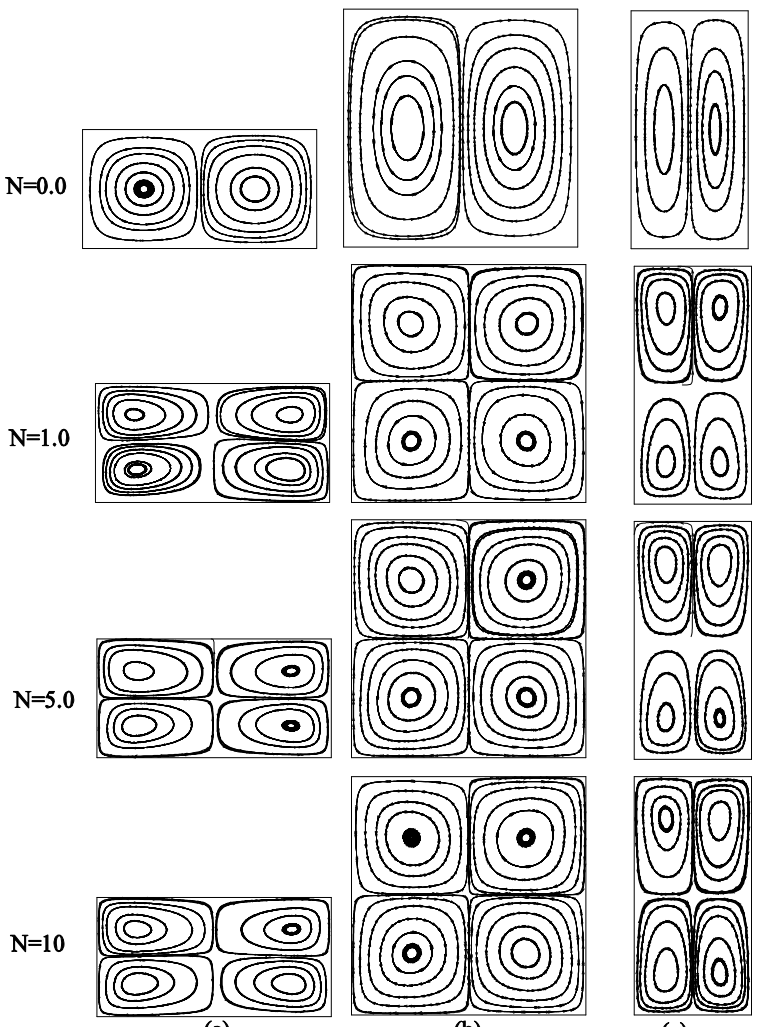

(c)

(i)

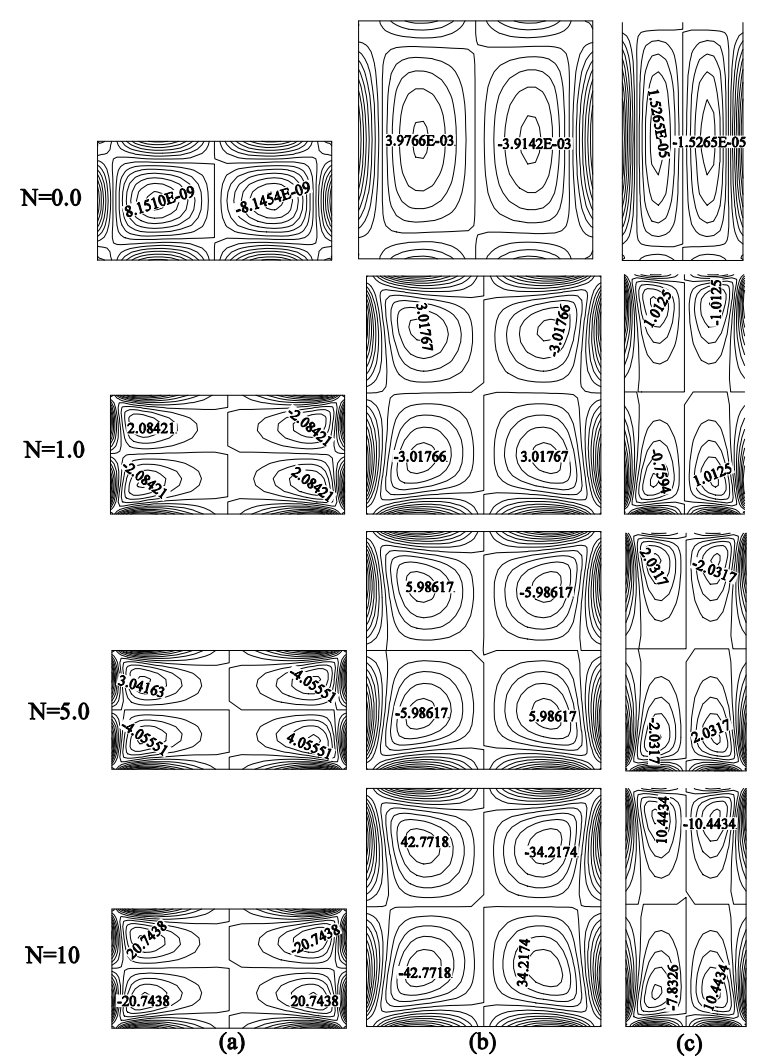

(ii)

Fig. 6 Effect of buoyancy ration on (i)Stream line and (ii) voritcity patterns in cavities of aspect ratios (a) 0.5 (b) 1.0 and (c) 2.0 at $\mathrm{Ra}=10^{3}$ 


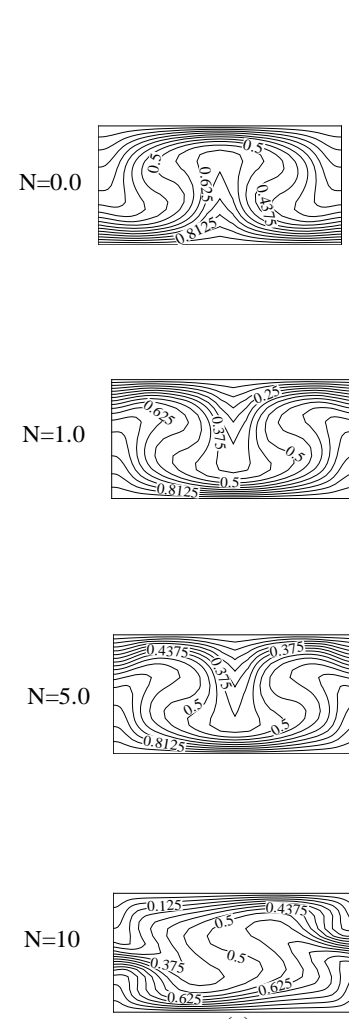

(a)
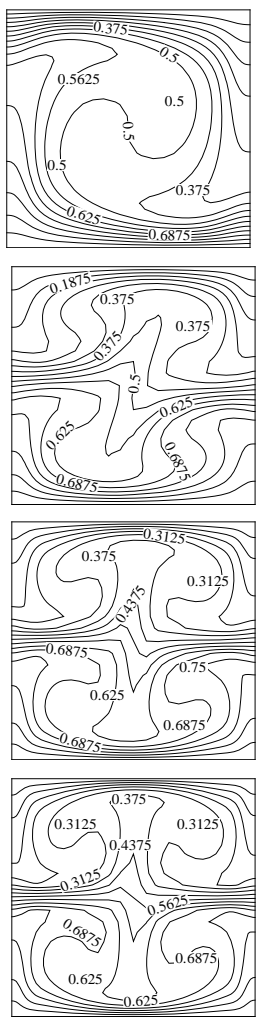

(b)

(i)
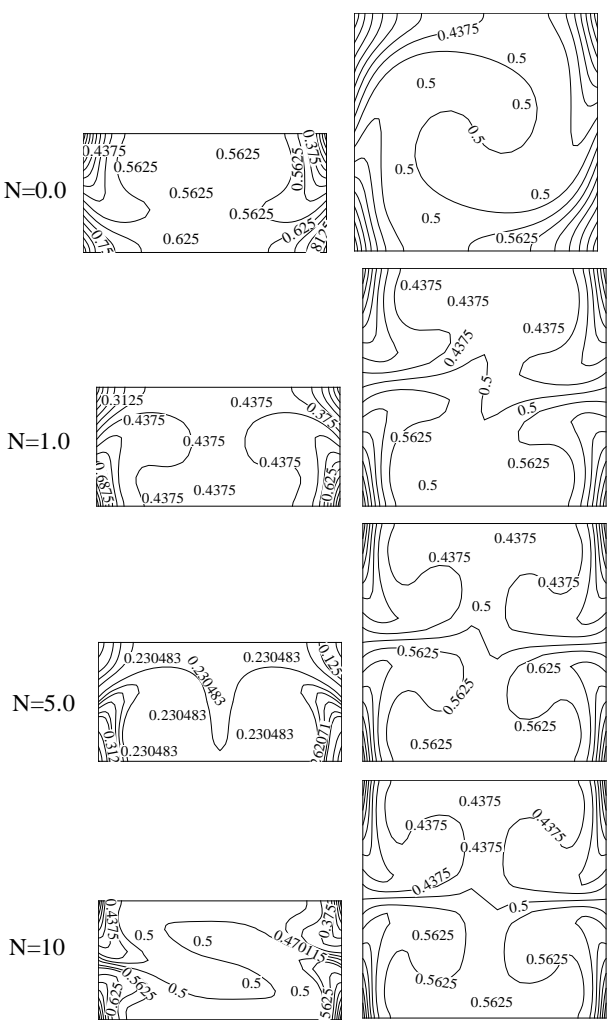

(b)
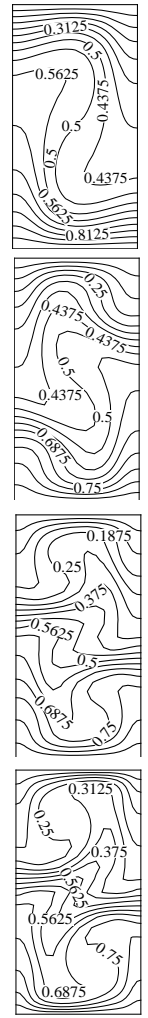

(c)
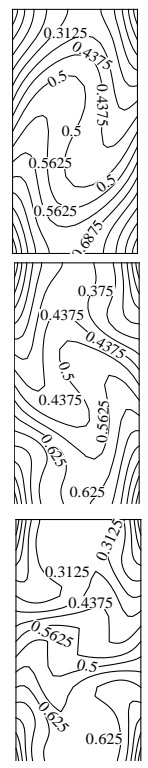

(c)

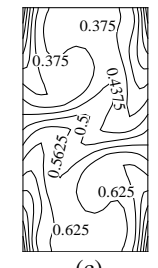

(ii)

Fig. 7 Effect of buoyancy ration on (i)Iso-therms and (ii) Isoconcentration lines in cavities of aspect ratios (a)0.5 (b) 1.0 and (c) 2.0 at $\mathrm{Ra}=10^{5}$ to set up fluid convection in case of square enclosure, isotherms here are observed as inverted ' $S$ ' shape . At this value, the other two enclosures exhibited only diffusive heat transfer with parallel temperature contours. As far as the variation in the shallow and deep enclosures are concerned no significant change is observed for $\mathrm{N}=0,1$ and 5. At $\mathrm{N}=10$, isotherms are observed curvy indicating the sign of convection currents In the case of square enclosure, isotherms are observed curvy with different pattern for different ' $N$ ' values which is due to the change in fluid flow pattern. Figure 9(i) shows the temperature contours at $\mathrm{Ra}=10^{3}$. At such low value of Rayleigh number the density gradients generated within the enclosure are found not strong enough to set up fluid circulation and hence heat transfer had taken place purely by diffusion. This trend is clearly observed in all the three enclosures for $\mathrm{N}$ varying from 0 to 5 . However at $\mathrm{N}=10$, slight fluid convection is found to be set up at the interior of the square enclosure. The reason may be that at $\mathrm{N}=10$, the solutal buoyancy force which is now the order of 10 times to the thermal buoyancy forces is strong enough to produce some fluid movement.

Figures 7(ii), 8(ii), 9(ii) show the distributions of concentration in all the three enclosures at different values of $\mathrm{N}$ for $\mathrm{Ra}=10^{5}, 10^{4}$ and $10^{3}$ respectively. The concentration varies from zero to 1 from the top end to the bottom end of the vertical walls. At Ra equal to $10^{5}$ (Figure 7(ii)), due to the effect of thermal buoyancy force decent fluid convection is set up in the enclosure. At $\mathrm{N}=0$, sharp concentration gradients are noticed in all the three enclosures. However, with increase in $\mathrm{N}$ from 0 to 1 , the gradients in the enclosures got altered due to the onset of solutal buoyancy forces. As noticed in the vorticity contours the strength of circulation has enhanced with increase in $\mathrm{N}$ value, for $\mathrm{N}=5$ in all the three enclosures iso-concentration lines observed steep indicating enhanced convective mass transfer and this has improved further when $\mathrm{N}$ is increased to 10 . When $\mathrm{Ra}$ is decreased to $10^{4}$ (Figure 8(ii)) at $\mathrm{N}=0$, the concentration gradients appeared symmetric about half section in shallow and deep enclosures with a straight horizontal line of 0.5 value at mid-way, this trend indicates the absence of convective transport of mass . But the square enclosure could exhibit convective mass transfer which is resembled by its concentration distribution. With increase in $\mathrm{N}$ value, shallow and deep enclosures does not exhibit any change in the gradients of concentration up to $\mathrm{N}=5$, whereas the gradients become very steep in the case of square enclosure. At $\mathrm{N}=10$, due to the strong contribution of solutal buoyancy force, mass transfer happened by convection in all the enclosures and the iso- concentration line at mid-section are now altered in shallow enclosure. . In the case of deep enclosure, the convective fluid flow produced concave and convex type iso-concentration lines. As seen from Figure 9(ii) for $\mathrm{Ra}=10^{3}$, the effect of change in the value of $\mathrm{N}$ has not shown any significant variation in the concentration profile.

The value of $\mathrm{N}$ is in relation to the strength of thermal buoyancy force, hence at $\mathrm{Ra}=10^{3}$ the buoyancy force due to temperature gradient is small, hence convective flow is not observed in the enclosure and the concentration distributions correspond only to pure diffusive mass transfer process.

\subsection{Nusselt number}

The convective heat transfer that takes place within the enclosure is better understood by computing the Nusselt number, which is the nondimensional temperature gradient at the hot wall. Figure 10 gives the local Nusselt number along the bottom wall in case of square enclosure for different Rayleigh number and buoyancy ratio. From Figure 10 a i.e at $\mathrm{Ra}=10^{5}$ it is observed that with increment in buoyancy ratio from 1.0 to 5.0 Nusselt number has improved. Nusselt number curve is observed symmetric about mid-section when $\mathrm{N}$ is 10 where solutal buoyancy forces play strong role and when $\mathrm{N}=0$ peak Nusselt number is observed at $X=0.75$, such variations in Nusselt number along the bottom wall are directly related to the fluid motion near bottom wall. With decrease in Rayleigh number to $\mathrm{Ra}=10^{4}$ a similar kind of Nusselt number pattern is observed with change in buoyancy ratio. Here the difference is the curves tend to become flatter, and the magnitude of 


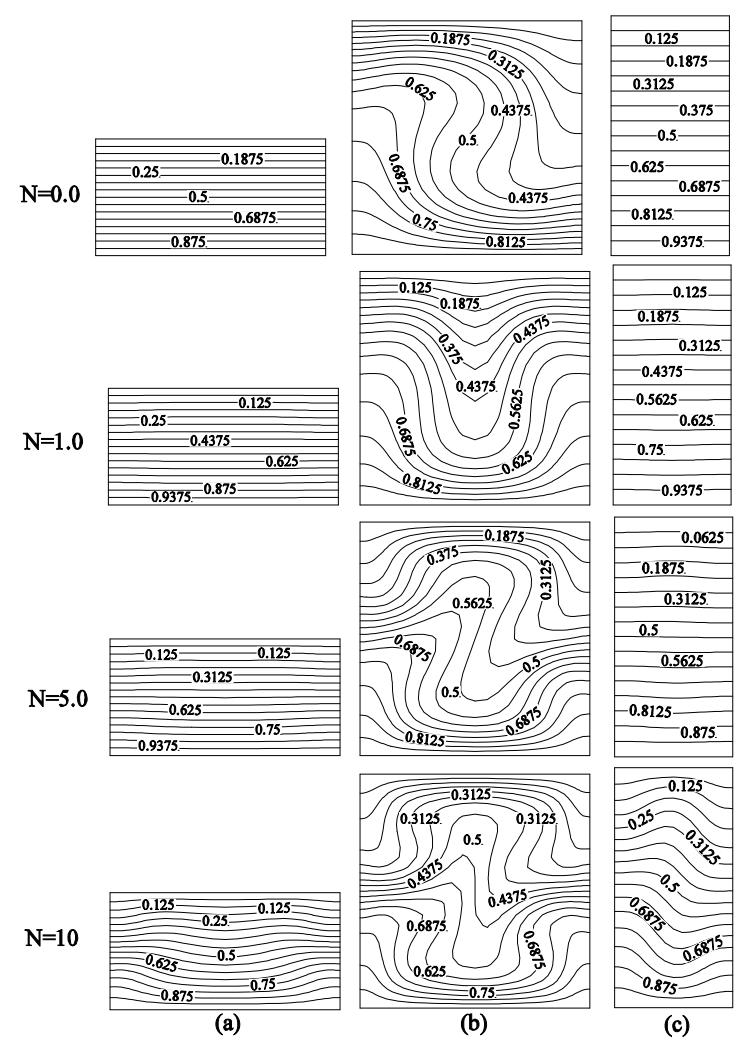

(i)
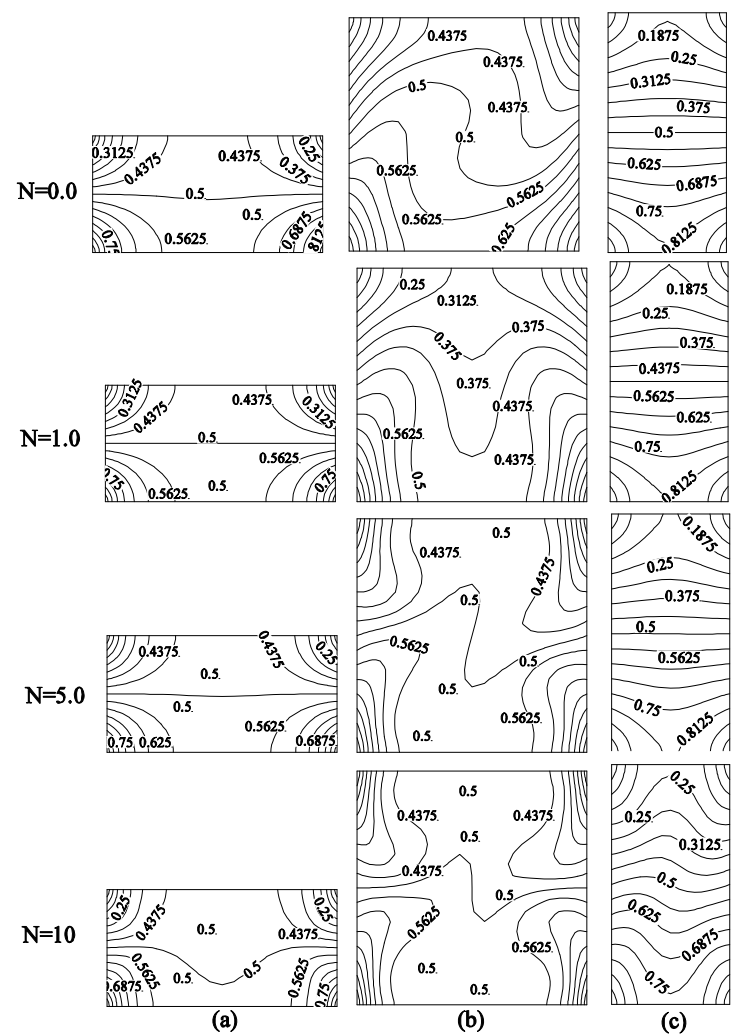

(ii)

Fig. 8 Effect of buoyancy ration on (i)Iso-therms and (ii) Isoconcentration lines in cavities of aspect ratios (a)0.5 (b) 1.0 and (c)2.0 at $\mathrm{Ra}=10^{4}$

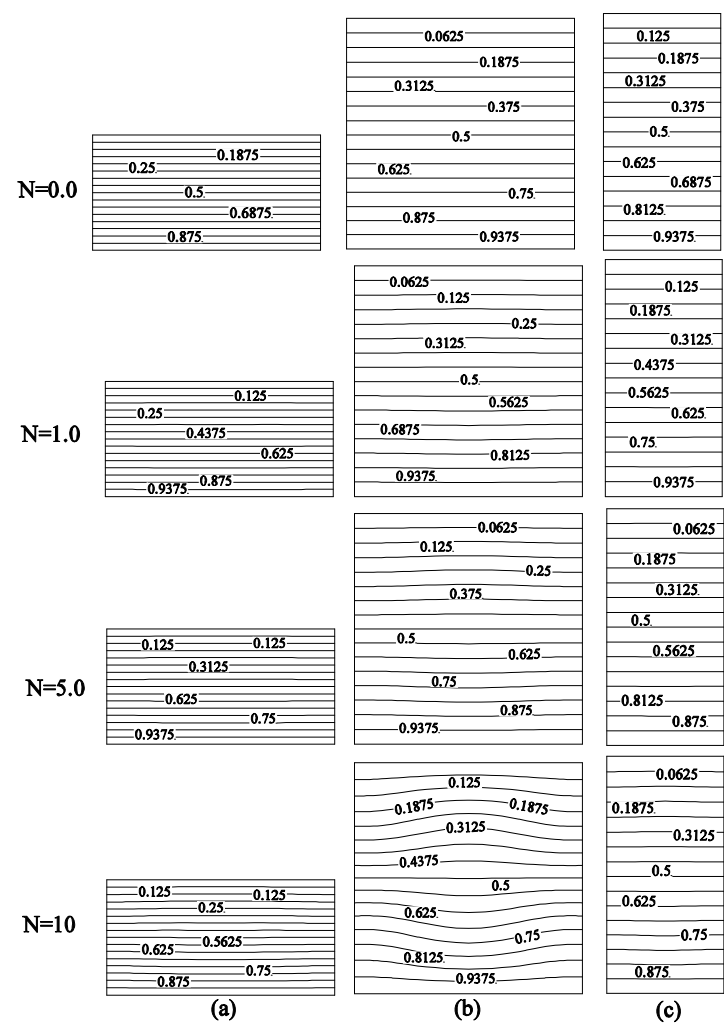

(i)

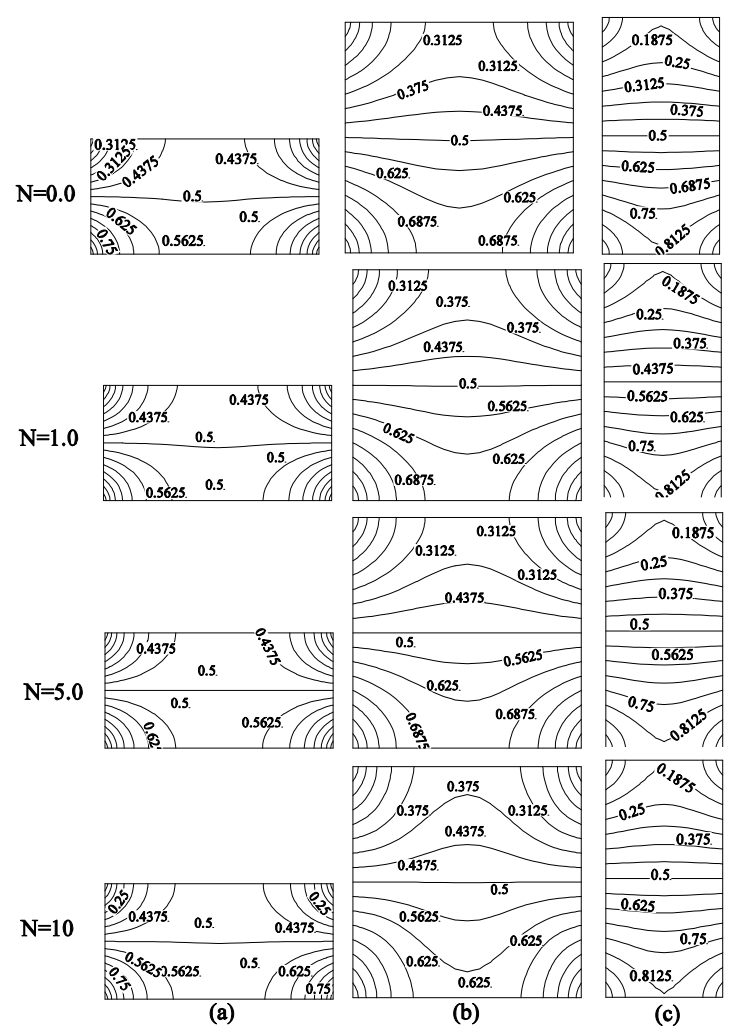

(ii)

Fig. 9 Effect of buoyancy ration on (i)Iso-therms and (ii) Isoconcentration lines in cavities of aspect ratios (a)0.5 (b) 1.0 and (c) 2.0 at $\mathrm{Ra}=10^{3}$ 


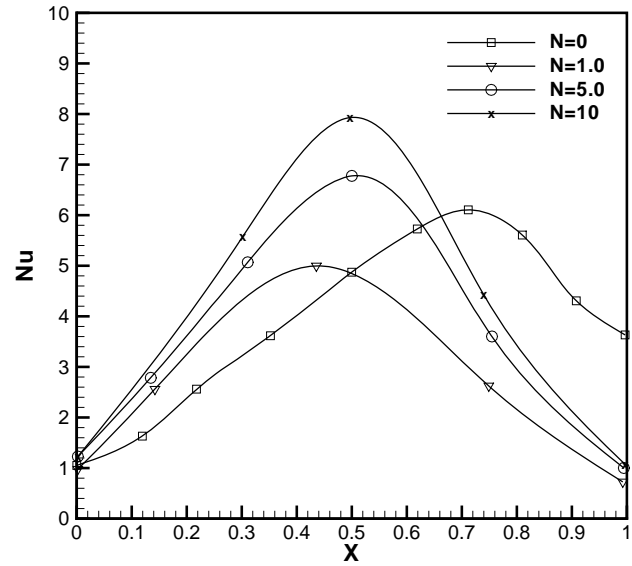

(a)

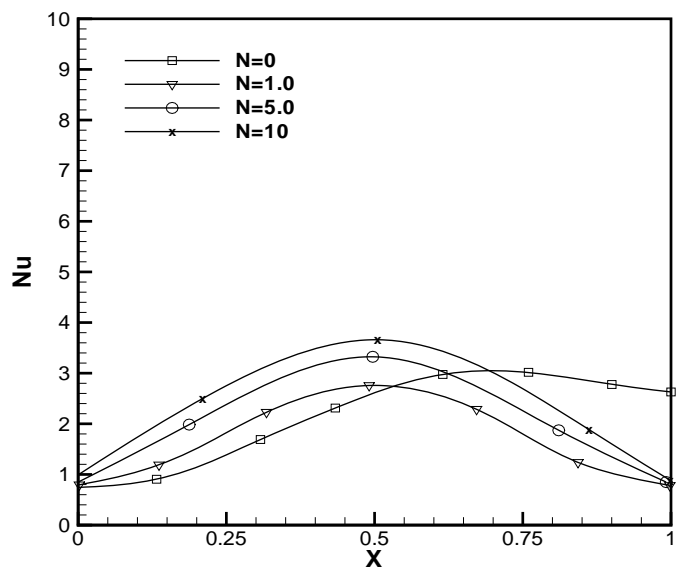

(b)

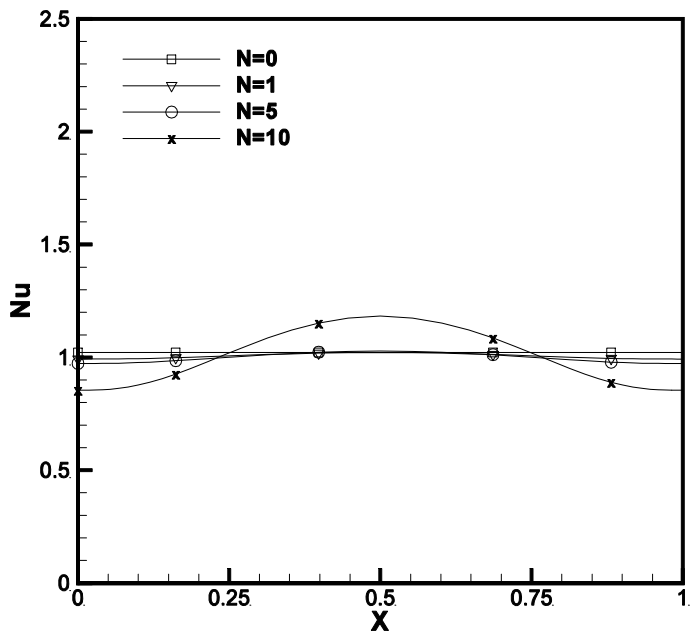

(c)

Fig. 10 Effect of buoyancy ratio on Nusselt number along the hot bottom wall in case of square cavity $(\mathrm{AR}=1.0)$ at different Rayleigh number (a) $R a=10^{5}$ (b) $R a=10^{4}$ and (c) $R a=10^{3}$

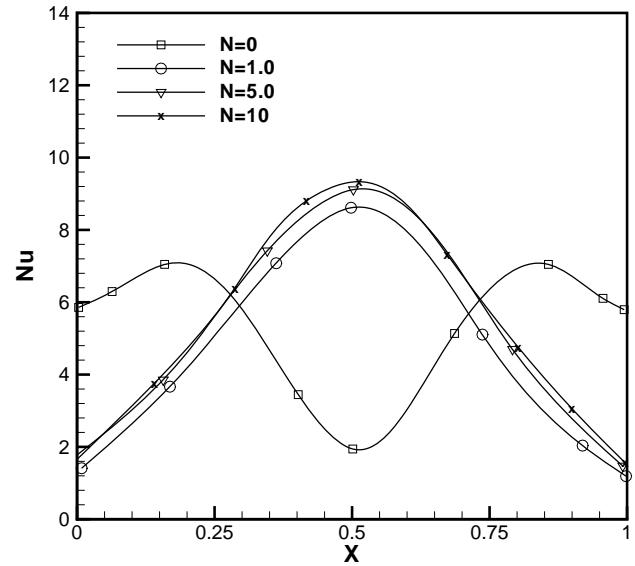

(a)

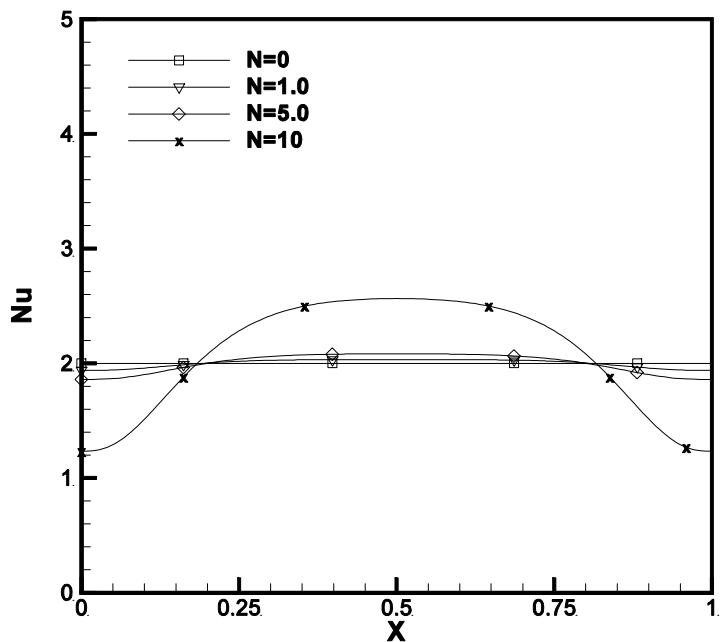

(b)

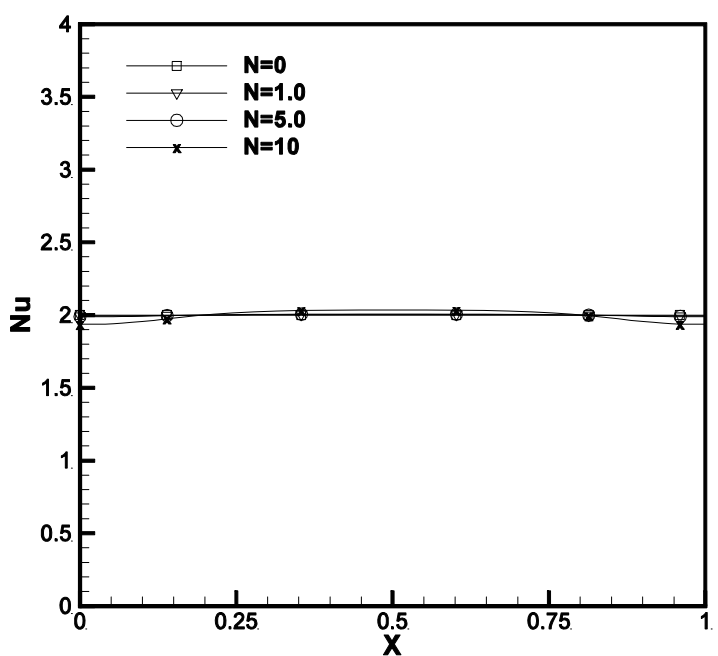

(c)

Fig. 12 Effect of buoyancy ration on Nusselt number along the hot bottom wall in case of shallow cavity $(\mathrm{AR}=0.5)$ at different Rayleigh number (a) $\mathrm{Ra}=10^{5}$ (b) $\mathrm{Ra}=10^{4}$ and (c) $\mathrm{Ra}=10^{3}$ 
Nusselt number has decreased due to reduced strength of buoyancy forces. With further reduction in buoyancy ratio except at $\mathrm{N}=10$ for all other buoyancy ratios the curves became completely flat indicating sign of very poor convection.

With increase in aspect ratio (see Figure 11) i.e in case of deep enclosure $(A R=2)$ Nusselt number curve became falter even at $\mathrm{Ra}=10^{4}$, and at $\mathrm{Ra}=10^{3}$ for all $\mathrm{N}=10$ also no sign of any significant variation is observed in Nusselt number along the bottom wall. Another important observation is that peak Nusselt number is found lower than that of square enclosure case for all three Rayleigh number. In case of shallow enclosure (see Figure 12) the peak Nusselt number that has registered is observed higher than square and deep enclosures. At $\mathrm{Ra}=10^{5}$ (Figure 12a) with increase in buoyancy ratio from $\mathrm{N}=1$ to 10 heat transfer rate has slightly increased although flow structure remained same. In case of $\mathrm{Ra}=10^{4}$ expect at $\mathrm{N}=10$ for all other cases no variation in Nusselt number is observed with along the bottom wall and for $\mathrm{Ra}=10^{3}$ even $\mathrm{N}=10$ has not been effective.

Table 3 Comparison of average Nusselt number for different Rayleigh number and buoyancy ratio.

\begin{tabular}{|l|l|l|l|l|l|l|l|l|l|}
\hline & \multicolumn{3}{|c|}{ Square } & \multicolumn{3}{c|}{ Deep } & \multicolumn{3}{c|}{ Shallow } \\
\hline $\mathrm{Ra} \rightarrow$ & $10^{3}$ & $10^{4}$ & $10^{5}$ & $10^{3}$ & $10^{4}$ & $10^{5}$ & $10^{3}$ & $10^{4}$ & $10^{5}$ \\
\hline $\mathrm{N}=0$ & 1.02 & 2.17 & 3.94 & 1.0 & 1.0 & 2.76 & 2.0 & 2.0 & 5.14 \\
\hline $\mathrm{N}=1$ & 1.0 & 1.94 & 3.08 & 1.0 & 1.0 & 2.64 & 2.0 & 2.0 & 5.12 \\
\hline $\mathrm{N}=2$ & 1.0 & 2.23 & 3.31 & 1.0 & 1.0 & 2.83 & 2.0 & 2.0 & 5.36 \\
\hline $\mathrm{N}=5$ & 1.0 & 2.25 & 3.99 & 1.01 & 1.01 & 3.14 & 2.0 & 2.04 & 5.54 \\
\hline $\mathrm{N}=10$ & 1.07 & 2.52 & 4.51 & 1.20 & 1.20 & 4.18 & 2.0 & 2.09 & 5.79 \\
\hline
\end{tabular}

Table 3 gives the report of average Nusselt number for the cases considered in this work. An important observation is minimum Nusselt number is noticed at $\mathrm{N}=1$ for all the cases this may happened due to competition between equally strong thermal and solutal buoyancy forces. The percentage increase in Nusselt number with change in buoyancy ratio from 0 to 10 is observed to be $51 \%$ for deep enclosure, $14.46 \%$ for square enclosure and only $12.6 \%$ for shallow enclosure at $\mathrm{Ra}=10^{5}$.At $\mathrm{Ra}=10^{3}$ and $10^{4}$ the effect of buoyancy ratio on average Nusselt number is observed relatively less. In case of $\mathrm{Ra}=10^{4}$ maximum of $20 \%$ for deep enclosure, $16.4 \%$ for square and $4.5 \%$ for shallow cavity are recorded . At $\mathrm{Ra}=10^{3} 20 \%$ increment is observed for deep cavity, $4.9 \%$ for square and $0 \%$ increment in case of shallow cavity are noticed. This tells the effect of buoyancy ratio is felt more in case of deep cavity where the relative distance between solutal boundaries are shorter than thermal boundaries.

\section{CONCLUSIONS}

A numerical study has been conducted on double diffusive natural convection phenomenon in the bottom heated enclosure of different aspect ratio under mass diffusive side walls. Finite element solution procedure has been used to solve governing equations and obtain the solution for the field variables vorticity, velocity, temperature and concentration. Simulation results have been obtained for convective heat transfer under varying Rayleigh number and buoyancy ratios in the range, $10^{5} \geq \mathrm{Ra} \geq 10^{3}$ and $0 \leq \mathrm{N} \leq 10$ respectively for enclosures of three aspect ratios $0.5,1$ and 2. Interaction of thermal and solutal buoyancy forces inside the enclosures resulted in following observations.

(i) Effect of solutal gradients imposed from boundary conditions greatly felt on fluid circulation inside the enclosure, in most of the cases solutal buoyancy forces had multiplied the convection cells and enhanced the fluid vorticity.

(ii) The maximum increase in the Nusselt number with increases in buoyancy ratio for deep enclosure, square and shallow enclosure are observed as 51\%, 14.5\% and $12.6 \%$ respectively.

(iii) Fluid vorticity got hampered slightly when both thermal and solutal buoyancy forces are of equal magnitude. And increase in strength of solutal buoyancy forces encouraged the formation of Quadra cell structures of greater vorticity strength.

(iv) At $\mathrm{Ra}=10^{5}$ where vorticity of fluid cells is appreciably high, with increase in buoyancy ratio any variation in stream line pattern shown significant influence on bottom wall Nusselt number.

(v) Although the stream line pattern varied with increase in buoyancy ratio no significant change is observed in Nusselt number at $\mathrm{Ra}=10^{4}$ and below especially in case of deep and shallow enclosures.

(vi) At $\mathrm{Ra}=10^{3}$ change in buoyancy ratio as not shown any effect on Nusselt number for all three aspect ratios and four cell structures with shape compatible to aspect ratio of enclosure are observed when $\mathrm{N}>0$.

\section{NOMENCLATURE}

\begin{tabular}{|c|c|}
\hline$A R$ & aspect ratio \\
\hline$C$ & concentration of species $\left(\mathrm{kg} / \mathrm{m}^{3}\right)$ \\
\hline$D$ & binary diffusion coefficient $\left(\mathrm{m}^{2 /} \mathrm{s}\right)$ \\
\hline$g$ & gravitational acceleration $\left(\mathrm{m} / \mathrm{s}^{2}\right)$ \\
\hline$H$ & height of the enclosure \\
\hline Le & Lewis number \\
\hline$N$ & buoyancy ratio \\
\hline$N u$ & local Nusselt number \\
\hline $\operatorname{Pr}$ & Prandtl number \\
\hline$R a$ & Rayleigh number \\
\hline$S c$ & Schmidt number \\
\hline Sh & local Sherwood number \\
\hline$t$ & time $(\mathrm{s})$ \\
\hline$T$ & temperature $(\mathrm{K})$ \\
\hline$u, v$ & horizontal and vertical velocity components, $\mathrm{m} / \mathrm{s}$ \\
\hline$U_{0}$ & lid velocity $(\mathrm{m} / \mathrm{s})$ \\
\hline$W$ & width of the enclosure \\
\hline$x, y$ & horizontal and vertical coordinates $(\mathrm{m})$ \\
\hline$X, Y$ & non dimensional coordinates \\
\hline Gree & Symbols \\
\hline$\alpha$ & thermal diffusivity $\left(\mathrm{m}^{2} / \mathrm{s}\right)$ \\
\hline$\beta_{C}$ & concentration volumetric expansioncoefficient $\left(\mathrm{m}^{3} / \mathrm{kg}\right)$ \\
\hline$\beta_{\mathrm{T}}$ & thermal volumetric expansion coefficient $\left(\mathrm{K}^{-1}\right)$ \\
\hline$\mu$ & dynamic viscosity(kg/s.m) \\
\hline$v$ & kinematic viscosity $\left(\mathrm{m}^{2} / \mathrm{s}\right)$ \\
\hline$\phi$ & non dimensional concentration of species \\
\hline$\theta$ & non-dimensional temperature \\
\hline$\rho$ & density $\left(\mathrm{kg} / \mathrm{m}^{3}\right)$ \\
\hline$\tau$ & non dimensional time \\
\hline$\omega$ & vorticity $(s-1)$ \\
\hline$\varsigma$ & non dimensional vorticity \\
\hline$\Delta$ & difference \\
\hline Subs & \\
\hline & average \\
\hline & cold \\
\hline $\mathrm{h}$ & hot \\
\hline
\end{tabular}

\section{REFERENCES}

Heather, D., Ashley, E., Ann, M., 2013, "Analysis of Chaotic Natural Convection in a Tall Rectangular Cavity with Non-Isothermal Walls," Frontiers in Heat and Mass Transfer (FHMT), 4 - 023004. http://dx.doi.org/10.5098/hmt.v4.2.3004

Manoj, K.T., Dipak, S., Rajsekhar, P., 2014, "Numerical Analysis of Natural Convection in a Right-Angle Triangular Enclosure," Frontiers in Heat and Mass Transfer (FHMT), 5 - 12.

http://dx.doi.org/10.5098/hmt.5.12 
Wang, J., Yang, M., and Zhang, Y., 2014, "Onset of Double Diffusive Convection in Horizontal Enclosure with Soret and Dufour Effects," International Journal of Heat and Mass Transfer," 78, 1023-1031. http://dx.doi.org/10.1016/j.ijheatmasstransfer.2014.07.064

Aouachria,Z., Rouichi,F. , Haddad, D., 2012, "Double Diffusion Effects on Convection in Flow on Vertical Plate Imbedded in a Porous Media," Frontiers in Heat and Mass Transfer (FHMT), 3 - 023004. http://dx.doi.org/10.5098/hmt.v3.2.3004

Kaladhar, K., Srinivasacharya,D., 2014, "Effects of Thermal and Solutal Stratification on Mixed Convection Flow along a Vertical Plate Saturated with Couple Stress Fluid," Frontiers in Heat and Mass Transfer (FHMT) 5 - 11 .

http://dx.doi.org/10.5098/hmt.5.11

Manoj, K., Triveni, D. S., Rajsekhar, P., 2015, "Convective Heat Transfer Analysis in an Arch Enclosure," Frontiers in Heat and Mass Transfer (FHMT), 6 - 2.

http://dx.doi.org/10.5098/hmt.6.2

Kumar, S., D., Krishan, M., and Thomas, H.R., 2011, "Effect of the Aspect ratio of a Heated Block on the Interaction Between Inertial and Thermosolutal Buoyancy Forces in a Lid- Driven Cavity," Numerical Heat Transfer, Part A Applications, 60, 7,604-628.

https://doi.org/10.1080/10407782.2011.609094

Kamotani, Y., Wang, L.W., Ostrach, S., and Jiang, H.D., 1985, "Experimental Study of Natural Convection in Shallow Enclosures with Horizontal Temperature and Concentration Gradients," International Journal of Heat and Mass Transfer," 28(1), 165-173. http://dx.doi.org/10.1016/0017-9310(85)90018-3

Costa, V.A.F., 1997, "Double Diffusive Natural Convection in a Square Enclosure with Heat and Mass Diffusive Walls," International Journal of Heat and Mass Transfer," 40(17), 4061-4071.

http://dx.doi.org/10.1016/S0017-9310(97)00061-6

Beghein, C., Haghighat, F., and Allardt, F., 1992, "Numerical Study of Double-Diffusive Natural Convection in a Square Enclosure," International Journal of Heat and Mass Transfer," 35(4), 833-846. http://dx.doi.org/10.1016/0017-9310(92)90251-M

Nishimura, T., Wakamatsu, M., and Morega, A.M., 1998, "Oscillatory Double-Diffusive Convection in a Rectangular Enclosure With Combined Horizontal Temperature and Concentration Gradients," International Journal of Heat and Mass Transfer, 41(11), 1601-1611. http://dx.doi.org/10.1016/S0017-9310(97)00271-8

Hyun, J.M., and Lee, J.W., 1990, "Double-Diffusive Convection in a Rectangle with Cooperating Horizontal Gradients of Temperature and Concentration," International Journal of Heat and Mass Transfer," 33(8), 1605-1617.

http://dx.doi.org/10.1016/0017-9310(90)90017-O

Chen, S., Tolke, J., and Krafczyk, M., 2010, " Numerical Investigation of Double-Diffusive (Natural) Convection in Vertical Annuluses with Opposing Temperature and Concentration Gradients," International Journal of Heat and Fluid Flow, "31,217-226. http://dx.doi.org/10.1016/j.ijheatfluidflow.2009.12.013

Han, H., and Kuehn, T. H., 1991, "Double Diffusive Natural Convection in a Vertical Rectangular Enclosure- II. Numerical study," International Journal of Heat and Mass Transfer, " 34(2), 461471.

http://dx.doi.org/10.1016/0017-9310(91)90265-G

Chouikh, R., Snoussi, L. B., and Guizani, A., 2007, "Numerical Study of the Heat and Mass Transfer in Inclined Glazing Enclosure, Application to a Solar Distillation Cell," Renewable Energy, 32, 15111524.

http://dx.doi.org/10.1016/j.renene.2006.07.001
Qin Q, Xia ZA, and Tian ZF., 2014, " High Accuracy Numerical Investigation of Double-Diffusive Convection in a Rectangular Enclosure with Horizontal Temperature and Concentration Gradients," International Journal of Heat and Mass Transfer, " 71, 405-423. http://dx.doi.org/10.1016/j.ijheatmasstransfer.2013.12.035

Alloui, I., Benmoussa, H., and Vasseur, P., 2010, "Soret and Thermosolutal Effects on Natural Convection in a Shallow Enclosure Filled with a Binary Mixture," International Journal of Heat and Fluid Flow," 31,191-200.

http://dx.doi.org/10.1016/j.ijheatfluidflow.2009.11.008

Nikbakhti, R., and Rahimi, A.B., 2012, "Double-Diffusive Natural Convection in a Rectangular Cavity with Partially Thermally Active Side Walls, "Journal of Taiwan Institute of ChemicalEngineering, 43, $535-541$.

http://dx.doi.org/10.1016/j.jtice.2012.02.010

Khodakhah, J., and Nikbakhti, R., 2016, "Numerical Investigation of Double Diffusive Buoyancy Forces Induced Natural Convection in a Cavity Partially Heated and Cooled from Sidewalls," Engineering Science and Technology an International Journal." 19(1), 322-337. http://dx.doi.org/10.1016/j.jestch.2015.08.003

Oueslati, F., Ben-Beya, B., and Lili, T.,2014, "Numerical Investigation of Thermosolutal Natural Convection in a Rectangular Enclosure of an Aspect Ratio Four with Heat and Solute Sources," Heat and Mass Transfer, 50(5), 721-736. https://doi.org/10.1007/s00231-013-1280-2

Jenaa, S.K., Mahapatra, S.K., Sarkar, A. and Chamkhac, A.J., 2015, "Thermo-Solutal Buoyancy-Opposed Free Convection of a Binary Ostwald-De Waele Fluid inside a Cavity Having Partially-Active Vertical Walls," Journal of the Taiwan Institute of Chemical Engineers, 51, 9-19.

http://dx.doi.org/10.1016/j.jtice.2015.01.007

Ostwald-De Waele Fluid Inside a Cavity Having Partially-Active Vertical Walls," Journal of the Taiwan Institute of Chemical Engineers, 51, 9-19.

https://doi.org/10.1016/j.jtice.2015.01.007

Nazari, M., Louhghalam, L., Kayhani, M.H., 2015, “Lattice Boltzmann Simulation of Double Diffusive Natural Convection in a Square Cavity with a Hot Square Obstacle," Chinese Journal of Chemical Engineering, 23, 22-30.

https://doi.org/10.1016/j.cjche.2014.10.008

Moufekkir, F., Moussaoui, M.A., Mezrhab, A., and Naji. H., 2015, "Study of Coupled Double Diffusive Convection-Radiation in a Tilted Cavity via a Hybrid Multi-Relaxation Time-Lattice Boltzmann-Finite Difference and Discrete Ordinate Methods," Heat and Mass Transfer, 51(4), 567-586.

https://doi.org/10.1007/s00231-014-1423-0

Ren. Q., and Chan, C.L.,2016,"Numerical Study of Double-Diffusive Convection in a Vertical Cavity with Soret and Dufour effects by Lattice Boltzmann Method on GPU," Int. J. Heat and Mass Transfer, 93,538-553.

https://doi.org/10.1016/i.ijheatmasstransfer.2015.10.031

Corcione, M., Grignaffini, S., and Quintino, A., 2015, “Correlations for the Double-Diffusive Natural Convection in Square Enclosures Induced by Opposite Temperature and Concentration Gradients," Int. J. Heat and Mass Transfer, 81,811-819. https://doi.org/10.1016/j.ijheatmasstransfer.2014.11.013

Turan, O., Chakraborty. N., and Poole R., J., 2012, "Laminar RayleighBénard Convection of Yield Stress Fluids in a Square Enclosure," Journal of Non-Newtonian Fluid Mechanics, "171-172, 83-96. http://dx.doi.org/10.1016/j.jnnfm.2012.01.006 